\title{
Digital Education Environment Within the Frame of Schooling: Pedagogic Approaches and Development Strategies
}

\author{
Lelchitsky I.D. ${ }^{1}$ Silchenko A.P. ${ }^{2}$ Tsurkan M.V. ${ }^{3, *}$ \\ ${ }^{1}$ Institute of Social Technologies and Teacher Education, Tver State University, Tver 170100, Russia \\ ${ }^{2}$ Department of mathematical and natural science education, Tver State University, Tver 170100, Russia \\ ${ }^{3}$ Department of Public Administration, Tver State University, Tver 170100, Russia \\ *Corresponding author.Email:080783@list.ru
}

\begin{abstract}
The paper elaborates and classifies pedagogic approaches and development strategies for digital educational environment within the frame of schooling. Doing this, the authors take into account the didactic relations, which appear in the process of schooling. The article identifies the following approaches: situational, activitybased, andragogic, outcome-based, systemic, socio-cultural and cultural. The authors distinguish between suggested notions. The proposed functional pattern for digital education environment has established several personified education strategies: theory and practice fusion, the unanimity of content-related and procedural aspects of teaching, human congruity, creativity, research point approach, teaching and IT technologies fusion, objectivity and standardization. The core and concurrent strategies have been defined. The results of the study are practically relevant for scientists, engaged pedagogics, educational management, digital economics.
\end{abstract}

Keywords: pedagogic approaches, digital education environment development, schooling, strategies

\section{INTRODUCTION}

Nowadays stable, predictable and simple SPOD-world [1] is being replaced by a rapidly changing VUCAworld, in which traditional values are changing and new strategies for further civilizational development are emerging. These strategies shall be able to face the challenges of the modern word that represent open information space.

Nowadays digital technologies have become vital for the human activity. They trigger fundamental changes in established human practices, both in personal and professional spheres of life.

The existing challenges urge us to give more accurate definition to the aim of education, to be more specific, the discourse of the learning process, which is responsible for education and upbringing of a person, who will be able to meet the constantly changing requirements of social and economic development. In this light, the teaching dominant of digital transformation of education has become extremely important, as well as preserving and improvement of teaching context in existing educational relations.

Therefore, the prevailing task is to develop a digital education environment, integrated into schooling process. The created system should be treated as an information product for further distribution.
Nowadays a project approach is widely employed in the federal public management with regard to the priorities of social and economic development of the state [2].

The relevance of the study is caused by the necessity to reach the goals of the Russian national project, named "Education" This project includes several federal projects, aimed at reaching certain national goals, in particular, at creating the environment that will ensure proper functioning of a digital world school.

The authors stick to the belief that if digital teaching packages are developed by means of a brand-new and innovative approaches, they will meet the requirements of the federal project, named "Digital education environment", the proposed didactic tools which should be given to teachers will enhance the improvement of modern teachers'skills and competences This, in its turn, will help to comply with the requirements of such federal projects as "Teacher of future", "Success for every child".

The development of digital educational environment is a relevant topic for many scientists from different countries.

The authors have analyzed several scientific works of Russian scientists and have found some of them quite prominent.

In particular, E.N. Shevchenko states that "when we use such strategies we should tap full potential of the pupils in all aspects: cognitive, creative, social and artistic" [2]. I.B. Gorbunova, I.O. Tovpitch in their paper state that "teaching community is able to change media space 


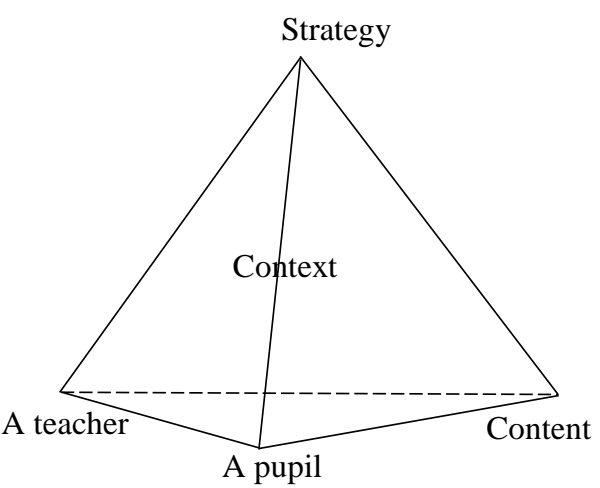

pursuant to given educational purposes and tasks through improving information literacy of all participants who are striving for changes and involved in learning process" [3].

O.V. Potasheva, M.V. Kuzmenko, M.I. Plutova O.B. "dwell upon regional experience of development and distribution of innovative learning resources that are vital for learning processes that are based on interlayer networks and are widely used in educational institutions"'[4].

But there is no study that systematizes and classifies the teaching approaches and strategies development for digital education environment in schooling.

The aim of the paper is to identify the main strategies that can be employed by the development of a new functional model for digital education environment in educational institutions. This goal can be achieved, if we compile a teaching approaches classification.

\section{STUDY METHODOLOGY}

The primary method of the study is the method of structural levels, which permits us to regard approaches and strategies of digital education environment development as the schooling elements.

The authors employ simulation method to visualize proposed approaches to the development of digital education environment and patterns for this environment:

\section{RESULTS AND DISCUSSION}

\subsection{The classification of approaches to the development of digital education environment.}

While identifying strategies and approaches to the development of digital education environment, we should consider didactic relations, arising out of the learning process. These relations can be illustrated by a three-dimensional model of a didactical tetrahedron [5]. The four peaks of the tetrahedron represent the four main components of a learning process - a teacher, a pupil, content and strategy; the tetrahedron sides reflect the relations between the components, while the entire didactical tetrahedron brings them together into comprehensive learning content. The scheme is shown in figure 1 .
Figure 1 A didactical tetrahedron

The authors believe that the following approaches, presented in figure 2 constitute a methodological basis for the development of digital education environment in educational institution.

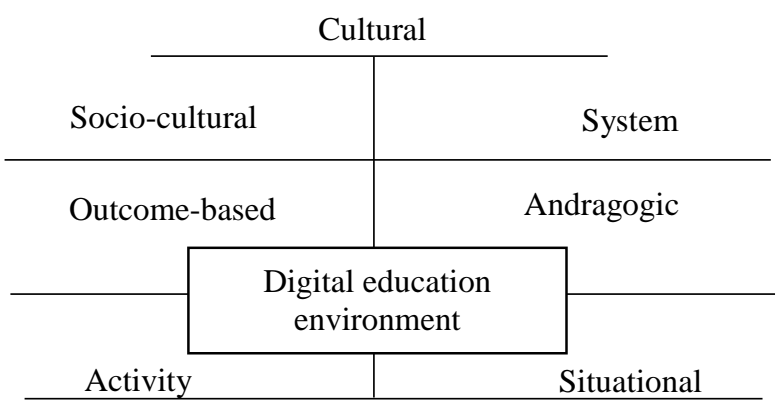

Figure 2 Development approaches for digital education environment

--The authors of this paper argue that the maim approaches, employed by the development of digital education environment are cultural and situational ones. In cultural approach the source of educational content is the social experience, which is accumulated in the culture and consists of four main components: knowledge, activity types, creative work experience and emotional and value-based attitude to the world.

There are the following types of experience: subject, metasubject (experience in application of universal ways of activity), creative, pragmatic (competence-based), personal (experience, connected with emotional and value-based attitude to the events, related to the environmental informatization). Each of them acts as a special component of educational content. Thus, it is the cultural approach that determines the grounds for classification of these experience types and identifies its procedural traits in educational activity. 
To acquire the mentioned cultural experience types we should set and resolve tasks which will correspond to the existing learning content. To reach this goal we should simulate situations in which different educational functions should be performed. This fact stipulates the choice and use of learning tools, methods and organizational forms of educational activity that will comply with the current learning content.

Within the given context the authors treat a situational pattern as a tool for cultural approach implementation by means of creating digital educational environment [6].

The core of the situational pattern is the situation, i.e. certain set of circumstances, which exert a great impact on the activity arrangement in particular period of time. This method helps us to understand, what tools and methods will be more efficient in reaching certain goals in a particular situation.

Despite the fact that situational approach is a probabilistic one and depends on chances, circumstances and a particular situation, it turns out to be quite useful in the process of learning. The researchers argue that such notion as "situation" reasonably exists in the theory of teaching, it reflects logic of pedagogic reality.

The authors of this paper define the term "situation" as a set of circumstances, which influences learning outcomes. A pedagogic situation is a set of circumstances, either created by a teacher or naturally in the process of studying. A pedagogic situation is a subset in the variety of all the possible situations, i.e. a situation is a multi-dimensional (polymetric) phenomenon.

The situational approach is a complex method, which gives the teacher a possibility to manage pedagogic situations, arising out of learning process, using a multipurpose managerial tool. By doing so, the teacher takes into account peculiarities of a subject and all the current conditions which possibly can influence the quality of learning activity [7].

The decision to use a situational approach by developing a pattern for digital education environment is stipulated by the following thesis "If a situation retains in the memory of a pupil, it means that this is something remarkable". Then comes the necessity to develop a didactic system, which consists of a set of situations, emerging as a result of the learning activity. These situations fulfil various educational functions and ensure proper acquirement of a learning content: subject and metasubject knowledge, ways of activity, creativity, activity experience, emotional and value-based attitude towards education.

A pedagogic situation is a period of learning activity, during which appear all the conditions that are vital for proper understanding of a certain element of content (type of experience), including tasks (assignment issue), settlement of which can facilitate the understanding of this element. A learning situation will urge the pupils to take actions, aimed at reaching certain educational goals. Depending on a situation type to such actions may belong: perceive and understand information (to form knowledge), to accept a task (to identify task essence and ways of settlement), to settle the task and demonstrate the results (to make a verbal or visual presentation or take some actions), to realize an acquired experience. The core element of a situation for pupils is to set a task and resolve it. Therefore, a learning activity is a consequence of situations and events, each of which helps pupils to achieve a certain learning result.

While creating learning situations the following strategies are used: unanimity of content-related and procedural aspects of teaching, (organization of activity, depending on the type of content that is to be used); interrelation and complementarity of different content elements as well as methods, which help to perceive the content; a context approach (considering life and professional goals of high-school students); the forms of learning activity should comply with the functions of corresponding learning situations.

If pupils handle with various situations, while they are placed in digital education environment, the teachers can track their results and predict, what way they will choose. The quality and depth of knowledge, obtained from each topic, depend on comprehensiveness and variety of situations, dwelling on various aspects of content. Each aspect urges pupils to involve in different types of activity.

Along with cultural and situational approaches, which have already been mentioned in this article, other approaches, such as socio-cultural, systemic, activity and competence-based and andragogic one, are also vital for the development of a digital education environment in educational institutions.

A socio-cultural approach helps us to find factors which explain the necessity to implement a digital education environment. A systemic approach gives us the possibility to treat a suggested digital education pattern as one of the key elements of a coherent learning activity and states that a change of any of its components will provoke a change of the whole system. An activity-based approach regards pupils as subjects of education and ensures their development in this role, increases their motivation to study.

A competence-based approach employs a system of universal learning activities, created within and by means of existing digital content. This approach boosts personal development of students.

Andragogic approach lays emphasis on socio psychological experience of students. This experience helps to track individual digital outcomes of each pupil and teach them to assess their own results. 
In this light, the aim of learning is that pupils should understand the content, which helps them to become subjects of culture, who possess life-purpose values and attitudes, who have all the skills necessary to adapt to digital transformations in society.

The individualization (or personification) is the essential feature of the development of a digital education environment in educational institutions. As a result, each pupil chooses his own way to resolve tasks, associated with personal development. In this study this phenomenon is defined as the process of a studentcentered education, which is aimed at boosting personal development of a pupil. This is expressed both by content and a special structure of a digital education environment, suggesting that learning activity should be organized, taking into account the individual differences of pupils, their traits, inclinations, interests, needs and previous experience.

\subsection{The development strategies for functional patters of digital education environment}

There are some strategies that are to be implemented by the development of digital education environment. They have established several personified education strategies: theory and practice fusion, the unanimity of contentrelated and procedural aspects of teaching, human congruity, creativity, research point approach, teaching and IT technologies fusion, objectivity and standardization.

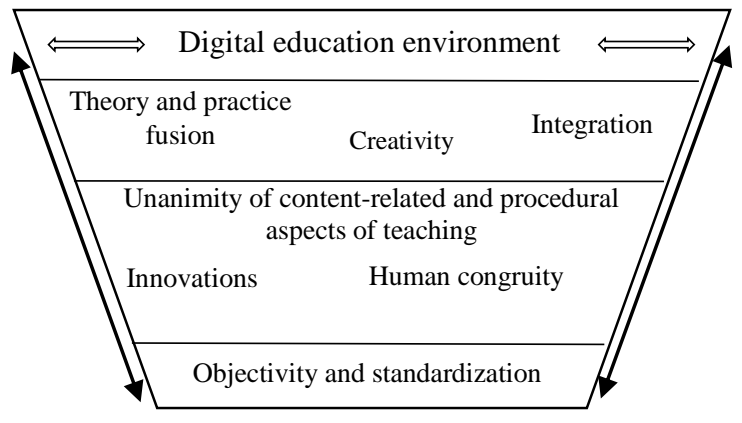

Figure 3 Development strategies for digital education environment

Theory and practice fusion means that digital teaching tools, which are based on Allis.school digital teaching platform cooperate with digital education environment by means of logical extension, for instance, teaching strategy and its five core components, goal setting, check of pupils 'knowledge, logical composition of topic under study, the analysis of typical errors and issues, arising in the process of studying certain subjects and applying changes to the learning process, depending on the results of this analysis, control of pupils 'individual work
The side of the didactical tetrahedron under the name Content - Strategy reflects the unanimity of contentrelated and procedural aspects of teaching, (i.e. organization of learning activity pursuant to the subject of learning). This strategy requires that the chosen teaching technologies should correspond to the learning content.

In the authors' opinion, the notion of human congruity combines the principles of humanization and humanitarization. The first principle implies the possibility to create your own educational path. The second one implies that the pupils should acquire cultural norms, seeing logical, cohesive images of objects, which have been created by a human for other humans, the pupils should acquire some value-based attitude to their own development and, consequently, to education and learning. They should realize that the education system is the intermediary, which connects their evolving personalities to society.

The creativity implies that the teacher acts as a learning content developer and employs different interactive multimedia tools. This is indispensable within digital education system. A modern teacher can't be called a professional, if he is not able to create digital education environment and involve pupils into it.

A research point faces the challenges of a digital era, when the activity of a teacher has to be multifaceted. Thus, the three key roles of any teacher in a learning process should be completely reinterpreted: the teacher has to be keen on all the aspects of the modern learning theory, so that he will be able to set and reach learning goals, handle with structures, digital content and rating system. The teacher also should have some research skills to be able to find links between goals, content and grades [8].

Teaching and IT technologies fusion means that a teacher should perform both the function of information processes and learning resources management, as well as didactic functions. If this strategy is used by developing digital education environment, it makes possible to set teaching technology components, to which a teacher resorts at all the four stages of his her professional activity. Thus, teachers can create a digital education environment that will be an essential part of learning process, not just a supplement.

It is worth mentioning that by the development of a digital education, we should take into account two features that are specific for a proposed pattern. They are educational results objectivity and professional standards of teaching activity.

Educational results objectivity implies that a teacher will easily use a comprehensive pedagogic technology that ensures instrumentalization and standardization of procedures that are responsible for obtaining objective and standardized educational results. The quality of these results meets the requirements of the federal state educational standards. This marks the switch from a subjective assessment of the pupils 'learning results to the monitoring that sets standards for the procedures of obtaining objective educational results. 
«Theoretical and methodological basis and

Professional standards of teaching activity shall represent a brand-new approach to his work. They shall be flexible and meet the requirements, set by changing didactic conditions of digital education environment. The teacher should use standardized didactic e-materials to comply with these requirements [9].

\section{CONCLUSION}

The executed analysis has driven us to the following conclusions:

The authors believe that the principal aim of digitalization in education is to preserve traditional teaching methods and to improve them by means of IT technologies.

Within the framework of a cultural approach to education we should treat learning content as a system that includes various types of a centuries-old cultural experience, which have been didactically processed.

Situational pattern is one of the kinds of cultural approach to education. This pattern is vital for the compilation and development of brand-new digital teaching packages.

The stated principle of educational results objectivity and professional standards of teaching activity can only be met, if there is any unified teaching technology, employing which it is possible to set professional standards for a teacher and ensure credibility of results, attained by pupils, without infringing on the teacher's creative work.

Thus, we should implement an efficient educational strategy that will help us to stimulate and individualize the learning process, to create digital education environment and apply it to the educational activity. In digital education environment various kinds of learning materials can be combined.

The proposed patterns and approaches selection procedure will be the tools for development of a brandnew digital education system.

For further development of this topic we should conduct a functional analysis of digital educational platform "Allis.School", using methods and strategies, mentioned in this paper. This platform meets the efficiency standards for the federal project "Modern school" and makes it possible to develop a brand-new teaching methodology for educational institutions.

The results of the study can be used by educational institutions, municipal and regional education management bodies, can be practically relevant for scientists, engaged pedagogics, educational management, digital economics

\section{ACKNOWLEDGMENT}

This scientific work was supported by the Russian Foundation for Basic Research under the project № 20-013-00150, titled development strategies employed for learning content in educational organizations

\section{REFERENCES}

[1] R.M. Yamilov. Combinatorial marketing as the core of efficient strategies, aimed at economic entities development. Practical marketing. 2016. № 1 (227). P. 3-10.

[2] M.V. Tsurkan. The priorities of education development within project approach. Volume: Forsite "Russia": a new industrial society. The future. The reports collection of Saint-Petersburg Economic Congress (SPEC-2018). Saint-Petersburg, 2019. P. 610-617.

[3] E.N. Shevchenko. A digital education system as a tool of pupils' knowledge improvement and a source, providing new opportunities at a math lesson.

Volume: Digital technologies as an aid to teacherdigest of the national scientific methodological conference with foreign participants. Cheboksary, 2020. P. 91-93.

[4] I.B. Gorbunova, I.O. Tovpitch. Information educational environment as a way of information literacy development for pupils and teachers in digital age school. Social development: Theory and practice 2015. № 7. P. 192-196.

[5] O.V. Potasheva, M.V. Kuzmenko, M.I. Plutova The effective use of digital technologies in education: positive experience of regional innovation platforms. Proceedings of the 1st International Scientific Conference "Modern Management Trends and the Digital Economy: from Regional Development to Global Economic Growth" (MTDE 2019) https://doi.org/10.2991/mtde-19.2019.140

[6] Bakhtina O.I., Monakhov V.M. A new approach to IT penetration and S\&T development of modern learning theory. The Moscow University Bulletin. Series 20: Teacher Education. 2018. № 2. P. 60-77.

[7] A.P. Silchenko, S.Yu. Tscherbakova. Innovations in the process of training future teachers for "Digital school". The data of VIII international research/practice conference "Teaching and learning mathematics at school and university: Innovations in information space»"(MATHEDU-2018) Kazan, 1721 of October, 2018. P. 194.

[8] A.P. Silchenko. "Innovative didactical eresources and materials for teachers in IT-education". International scientific journal "Modern IT 
technologies and IT education”, Volume 13 №2, 2017. P. 122-130

[9] A.P. Silchenko. Situational pattern within the frame of cultural approach to studying school subjects (as exemplified by computer studies at primary and secondary school).Pedagogics in Russia and abroad. 2019. № 3(60). P. 121-137.

[10]. A.P. Silchenko. Situational strategy in teaching. Collection of scientific works for national research/ practice conference "Traditional and innovative methods in professional activity and development of a teacher", Institute of Social Technologies and Teacher Education, Tver State University, - Tver. 2017, P.139-143. 